\title{
Effect of Imiquimod on Cytokine Induction in First Trimester Trophoblasts
}

\author{
Jerry M. Manlove-Simmons, ${ }^{1}$ Fadi M. Zaher, ${ }^{1}$ Mark Tomai, ${ }^{2}$ \\ Bernie Gonik, ${ }^{1}$ and David M. Svinarich ${ }^{1 *}$ \\ ${ }^{1}$ Department of Obstetrics and Gynecology, Wayne State University School of Medicine, Detroit, MI \\ ${ }^{2}$ Department of Pharmacology, $3 M$ Pharmaceuticals, St. Paul, $M N$
}

\begin{abstract}
Objectives: Imiquimod (IQ) is used clinically for the topical treatment of external genital warts. IQ is an immune response modifier and induces the expression of interferon- $\alpha$ and other cytokines in human Peripheral Blood Monocytes (PBMC). Trophoblasts have been previously shown to express inflammatory cytokines upon lipopolysaccharide (LPS) stimulation. The objective of this study was to evaluate the ability of IQ to induce transcription of cytokines in trophoblasts.

Methods: A transformed human first trimester trophoblast cell line, HTR-8/SVneo, was cultured in DMEM containing IQ at concentrations of 0 to $5.0 \mathrm{\mu g} / \mathrm{ml}$. 3-(4,5-dimethylthiazol-2-yl)-2,5diphenyl tetrazolium bromide (MTT) viability assays were conducted to control for any druginduced cell death. Total RNA was isolated from trophoblasts at 0,8 and 24 hours of culture and Reverse Transcription-Polymerase Chain Reaction (RT-PCR) was conducted using specific amplimers for the inflammatory cytokines interleukin (IL)-1 $\alpha$, IL-1 $\beta$, IL-6 and IL-8. RT-PCR of $\beta$-actin was performed to control for equal RNA loading.

Results: RT-PCR was unable detect an increase in either IL-1 $\alpha$, IL-1 $\beta$, IL-6 or IL-8 mRNA in first trimester trophoblasts cultured in the presence of 0 to $5.0 \mu \mathrm{g} / \mathrm{mL}$ of IQ for up to 24 hours. RT-PCR confirmed equal RNA loading and M'TT viability assays did not show loss of cell viability at concentrations of IQ up to $5.0 \mathrm{\mu g} / \mathrm{ml}$.

Conclusions: IQ, at the concentrations tested, did not induce the transcriptional expression of inflammatory cytokines in human first trimester trophoblasts. These data suggest that IQ would not induce the expression of inflammatory cytokines in placental trophoblasts. Infect. Dis. Obstet. Gynecol. 8:105-111, 2000. ๑2000 Wiley-Liss, Inc.
\end{abstract}

imiquimod; trophoblast; cytokines; herpes; immunomodulation

Imiquimod (IQ), [1(2-methylpropyl)-1h-imidazo [4,5-c]quinolin-4-amine], belongs to a class of imidazoquinolines with immunomodulatory characteristics. IQ is commonly used in the treatment of genital warts. This heterocyclic amine, which has potent antiviral and antitumor activity, stimulates the in vitro production of interferon- $\alpha$ (IFN- $\alpha)$, interleukin-1 $\alpha$ (IL-1 $\alpha$ ), interleukin-1 $\beta$ (IL-1 $\beta$ ), in- terleukin-6 (IL-6) and interleukin-8 (IL-8). ${ }^{1-3}$ Mononuclear phagocytes have been shown to be the cell type that is largely responsible for the expression of these cytokines following treatment with IQ. ${ }^{2-3}$ The induction of these cytokines is through transcriptional activation of cytokinespecific mRNA's. ${ }^{1}$ Placental trophoblasts share many phenotypic similarities with monocytes and

Grant sponsor: 3M Pharmaceuticals, St. Paul, MN.

*Correspondence to: David M. Svinarich, Ph.D., Wayne State University School of Medicine, Department of Obstetrics and Gynecology, C.S. Mott Center, 275 E. Hancock Ave., Detroit MI 48202. E-mail: d.svinarich@wayne.edu 
may therefore be affected by the immunomodulatory characteristics of IQ.

The human placenta is a multifunctional endocrine organ that serves as both a mechanical and immunological barrier against the vertical transmission of infectious agents. Placental trophoblasts are critical components of this barrier and have been shown to express a variety of both proinflammatory and immunoregulatory cytokines including IL- $1 \alpha$, IL-1 $\beta$, IL-6 and IL-8, when stimulated. ${ }^{4}$ These cytokines presumably function to elicit and modulate inflammatory immune responses, promote trophoblast differentiation and aid in maintaining normal placental function. ${ }^{5}$ Use of this drug during pregnancy could potentially alter the normal cytokine milieu at the maternal-fetal interface and therefore adversely affect trophoblast and hence placental function. This study was conducted to determine if IQ is capable of altering the transcriptional expression of immunomodulatory cytokines in human first trimester trophoblasts in vitro.

\section{SUBJECTS AND METHODS Cell Culture}

HTR-8/SVneo cells, ${ }^{6}$ derived from human first trimester extravillous trophoblasts, possess a normal trophoblast morphology and express cytokeratin, human chorionic gonadotrophin and type IV collagenase. Cells were grown to confluency in Dulbecco's Modified Eagle's Medium (DMEM) (SIGMA, St. Louis, MO), supplemented with $10 \%$ non-heat inactivated fetal bovine serum, $1 \% \mathrm{~L}$-glutamine, 50 $\mathrm{U} / \mathrm{mL}$ penicillin and $5 \mu \mathrm{g} / \mathrm{mL}$ streptomycin (GIBCO BRL, Gaithersburg, MD). Cells were cultured at $37^{\circ} \mathrm{C}$ in an atmosphere of $5 \% \mathrm{CO}_{2}$ in 75 $\mathrm{cm}^{2}$ flasks (VWR Scientific Products, Chicago, IL).

\section{Experimental Culture Conditions and RNA Isolation}

Confluent HTR-8/SVneo monolayers were washed three times in $4 \mathrm{~mL}$ of DMEM prior to culture under experimental conditions. Cells were subsequently cultured in media alone or in the presence of various concentrations ( 0 to $5.0 \mu \mathrm{g} / \mathrm{mL}$ ) of $\mathrm{IQ}$ for 0,8 or 24 hours. At each time point, total RNA was isolated from cells using the TRIzol ${ }^{\circledR}$ Reagent (GIBCO BRL, Gaithersburg, MD), in accordance with the manufacturers' instructions. RNA integrity was assessed by agarose gel electrophoresis and quantitated spectrophotometrically at $260 / 280 \mathrm{~nm}$.
Contaminating genomic DNA was digested with 4 U/sample of RQ1 DNase in 1× DNase buffer (Promega, Madison, WI), for $1.5 \mathrm{hr}$ at room temperature. This trophoblast cell line has been shown previously to express various inflammatory cytokines following lipopolysaccharide induction. ${ }^{4}$

\section{Cell Viability Assay}

Cell viability in media alone or in the presence of IQ $(0$ to $5.0 \mu \mathrm{g} / \mathrm{mL})$, was examined following 0,8 and 24 hours of culture. A rapid colorimetric assay utilizing the tetrazolium salt of MTT (3-(4,5dimethylthiazol-2-yl)-2,5-diphenyl tetrazolium bromide) (SIGMA), was conducted as described previously. ${ }^{7}$ Assays were performed in triplicate using a 96-well microtitre plate format and absorbances were determined using a plate-reading spectrophotometer (Ceres UV900HDI, Bio-TEK Instruments Inc., Winooski, VT) at a reference wavelength of $630 \mathrm{~nm}$ and a test wavelength of 570 nm.

\section{Reverse Transcription-Polymerase Chain Reaction}

RT-PCR amplification was conducted using amplimers to IL- $1 \alpha$, IL-1 $\beta$, IL-6, IL-8 and $\beta$-actin (IDT Technologies, Coralville, IA). Sequence data for the construction of amplimers was obtained from the public domain. Total RNA $(1 \mu \mathrm{g})$ was reverse transcribed and the cDNA amplified in a 50 $\mu \mathrm{L}$ reaction volume containing $1 \times$ buffer (Perkin Elmer Applied Biosystems, Norfolk, CT), $0.5 \mathrm{mM}$ sense and anti-sense primers, $2.0 \mathrm{mM} \mathrm{Mn}(\mathrm{OAc})_{2}$, $0.15 \mathrm{mM} d \mathrm{dTPs}$, and $5 \mathrm{U} /$ reaction of r'T th enzyme (Perkin Elmer Applied Biosystems, Norfolk, CT). The PCR reaction was overlaid with $50 \mu \mathrm{L}$ of sterile mineral oil and reverse transcription occurred for $60 \mathrm{~min}$ at $60^{\circ} \mathrm{C}$ followed by a denaturation step at $95^{\circ} \mathrm{C}$ for $2 \mathrm{~min}$. PCR amplification was performed at a denaturation temperature of $95^{\circ} \mathrm{C}$ for $45 \mathrm{sec}$ and an annealing temperature of either $52^{\circ} \mathrm{C}$ (IL-1 $\beta$ ) or $55^{\circ} \mathrm{C}$ (IL-1 $\alpha$, IL-6, IL-8 and $\beta$-actin), for $45 \mathrm{sec}$ and 35 cycles. This was followed by a terminal extension cycle at $72^{\circ} \mathrm{C}$ for $15 \mathrm{~min}$. Reverse transcription and PCR amplification were conducted in a Perkin Elmer 480 DNA thermocycler (Perkin Elmer Applied Biosystems). PCR products were resolved by agarose gel electrophoresis and product sizes were estimated by comparison with a molecular size standard (Pvu II digest of $\lambda$ bacte- 
riophage DNA). $\beta$-actin amplimers and where possible, cytokine amplimers, were designed to span intronic regions in order to control for the presence of contaminating genomic DNA. Levels of cytokine and $\beta$-actin mRNA were titrated by serial dilution prior to reverse transcription, in order to remain within the linear range of the PCR amplifications (data not shown). All reaction sets included negative PCR and negative RNA controls.

\section{RESULTS}

HTR-8SVneo cell viability was examined following 0,8 and $24 \mathrm{~h}$ of culture in the presence of IQ. No concentration-dependent or time-dependent change in cell viability was detected during the course of this study (Fig. 1). Total RNA was isolated from HTR-8SVneo cells grown under experimental and control conditions for R'T-PCR. RNA integrity was confirmed by agarose gel electrophoresis (Fig. 2). RT-PCR amplification of $\beta$-actin was conducted to ensure equal RNA loading throughout the experiment. RT-PCR analysis demonstrated the appearance of a single $309 \mathrm{bp} \beta$-actin product of essentially equal intensity among all experimental and control sets (Fig. 3). RT-PCR analysis was subsequently conducted to determine the relative mRNA levels of specific immunomodulatory and proinflammatory cytokines. RTPCR amplification using amplimers to IL-1 $\alpha$ (Fig. 4), IL-1 $\beta$ (Fig. 5), IL-6 (Fig. 6) and IL-8 (Fig. 7), yielded discrete products of $500 \mathrm{bp}, 398 \mathrm{bp}, 494 \mathrm{bp}$ and $217 \mathrm{bp}$, respectively. No concentrationdependent or time-dependent effect of IQ on cytokine mRNA levels in human trophoblasts was noted.

\section{DISCUSSION}

IQ is safe and effective for the topical treatment of genital warts. ${ }^{8-9}$ The anti-viral nature of this drug is attributed largely to the induced expression of IFN- $\alpha$ and other immunomodulatory cytokines by monocytes. ${ }^{1}$ Trophoblasts, which are phenotypically similar to monocytes, are known to express immunomodulatory and proinflammatory cytokines following induction by infection stimuli. ${ }^{4}$ This study examined the ability of IQ to induce the in vitro expression of similar cytokines in first trimester trophoblasts. Such induction may be contraindicated during pregnancy because exposure to an altered cytokine milieu could adversely affect
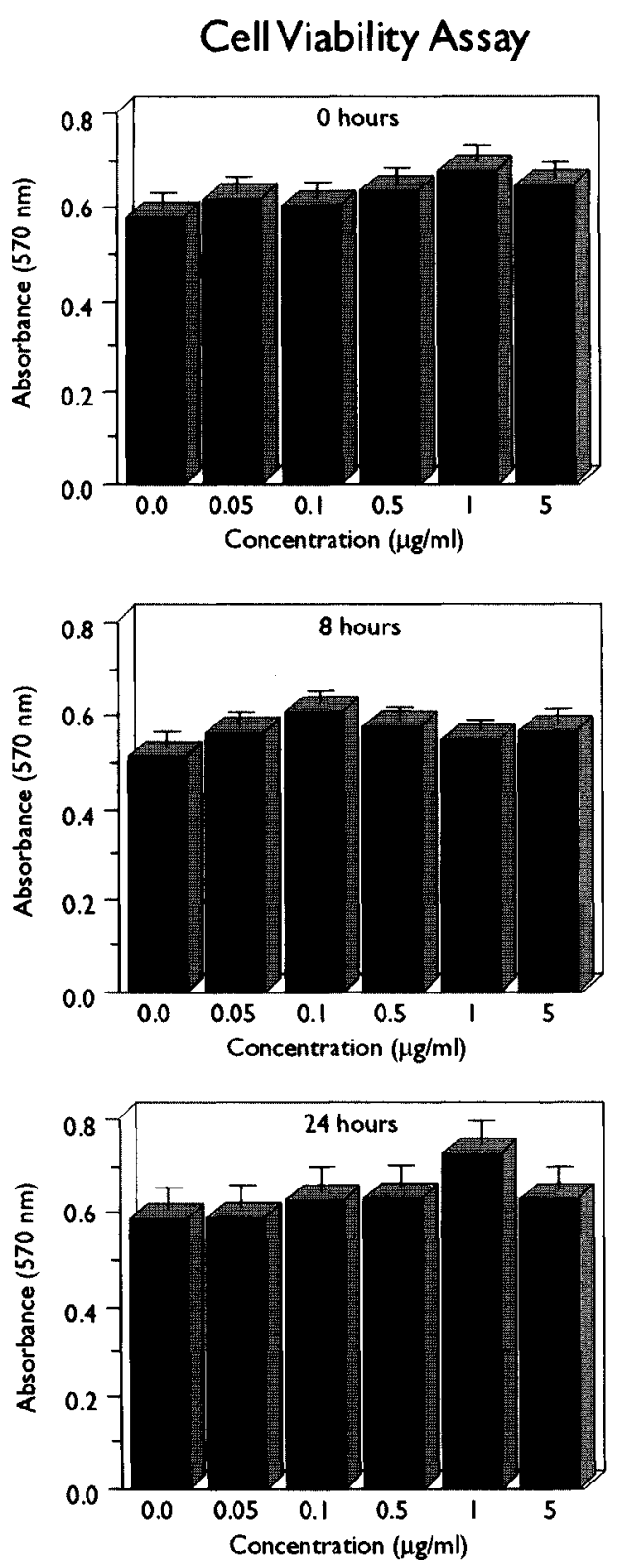

Fig. I. HTR-8SVneo cell viability assay. Viability of first trimester trophoblasts was evaluated following culture in the presence of IQ $(0,0.05,0.1,0.5,1.0$ or $5.0 \mu \mathrm{g} / \mathrm{mL})$ for Oh (top), $8 \mathrm{~h}$ (middle) and $24 \mathrm{~h}$ (bottom).

trophoblast function or fetal immune development. ${ }^{10-11}$

RT-PCR demonstrated neither a concentrationdependent nor time-dependent induction of IL$1 \alpha$, IL-1 $\beta$, IL-6 or IL-8 in first trimester trophoblasts by IQ. The presence of RNA transcripts to these cytokines in trophoblasts cultured under control conditions is consistent with previous observations suggesting that these cytokines may be ex- 


\section{RNA- Integrity}
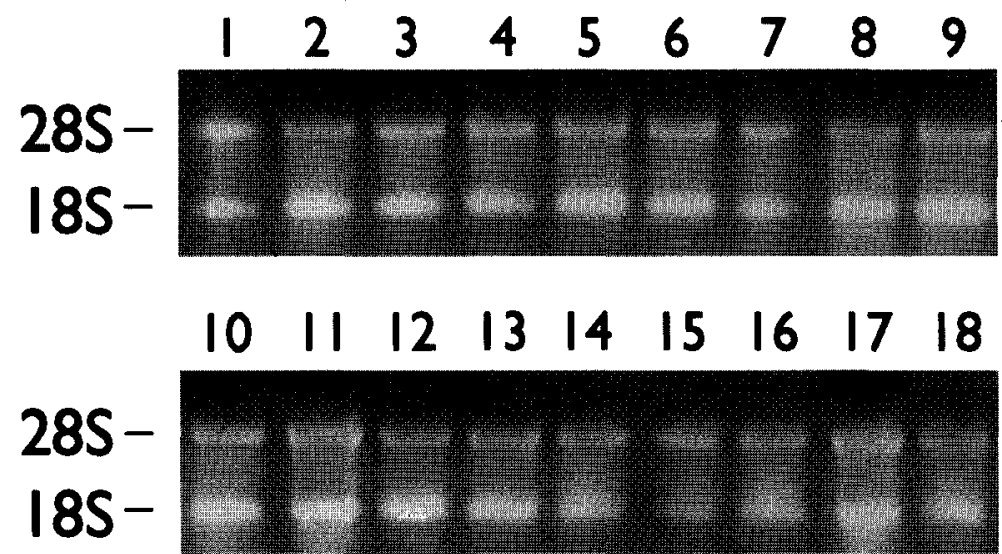

Fig. 2. Determination of RNA integrity. Total RNA was isolated from first trimester trophoblasts cultured in the presence of IQ $(0,0.05,0.1,0.5,1.0$ and $5.0 \mu \mathrm{g} / \mathrm{mL}$ ) for Oh (lanes I-6), 8h (lanes 7-12) and 24h (lanes 13-18).

\section{$\beta$-Actin}
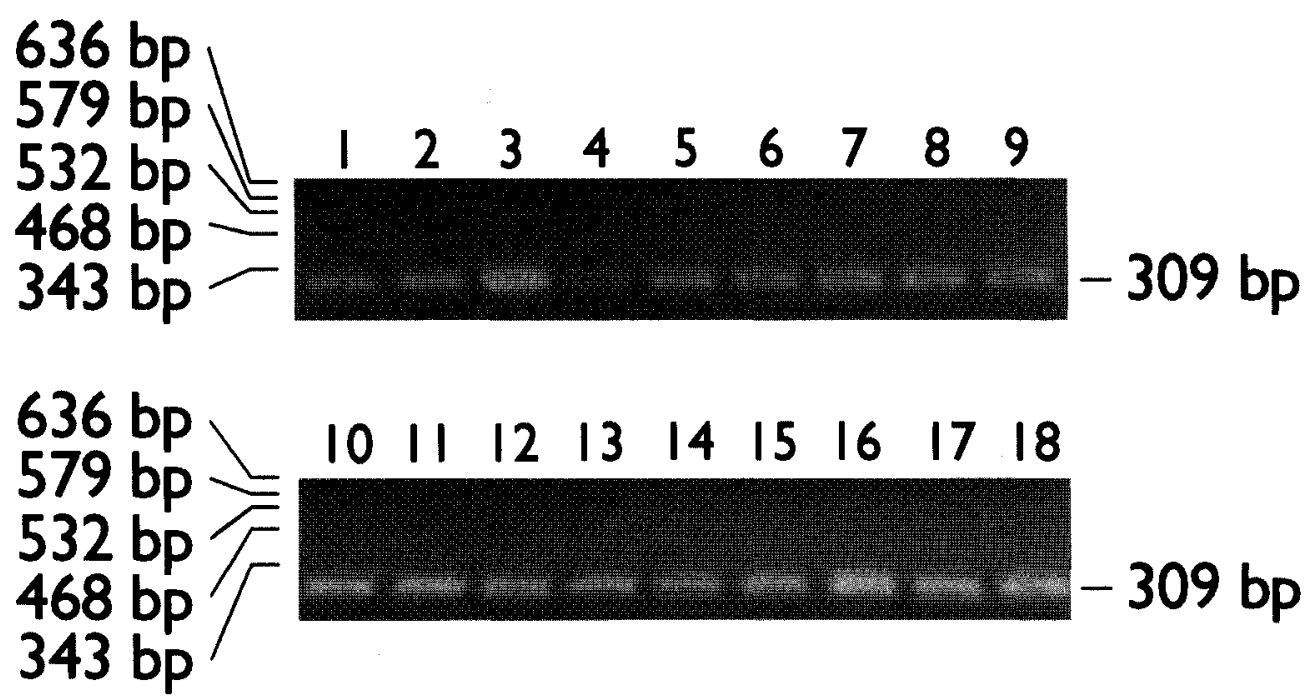

Fig. 3. Transcriptional expression of $\beta$-actin in trophoblasts. Human $\beta$-actin was amplified from trophoblasts to control for equal loading of RNA. RT-PCR amplification yielded a single $309 \mathrm{bp}$ product of nearly equal intensity from trophoblasts cultured in the presence of IQ $(0,0.1,0.5,1.0$ and $5.0 \mu \mathrm{g} / \mathrm{mL}$ ) for Oh (lanes I-6), 8h (lanes 7-12) and 24h (lanes 13-18).

pressed at a low constitutive level. ${ }^{4}$ These results are also consistent with previous observations suggesting that $I Q$ is largely immunomodulatory for antigen presenting cells such as monocytes and macrophages. Resident macrophages and monocytes present within the placenta may therefore respond to IQ treatment by expression of cytokines. These data support the hypothesis that IQ 


\section{IL-I $\alpha$}
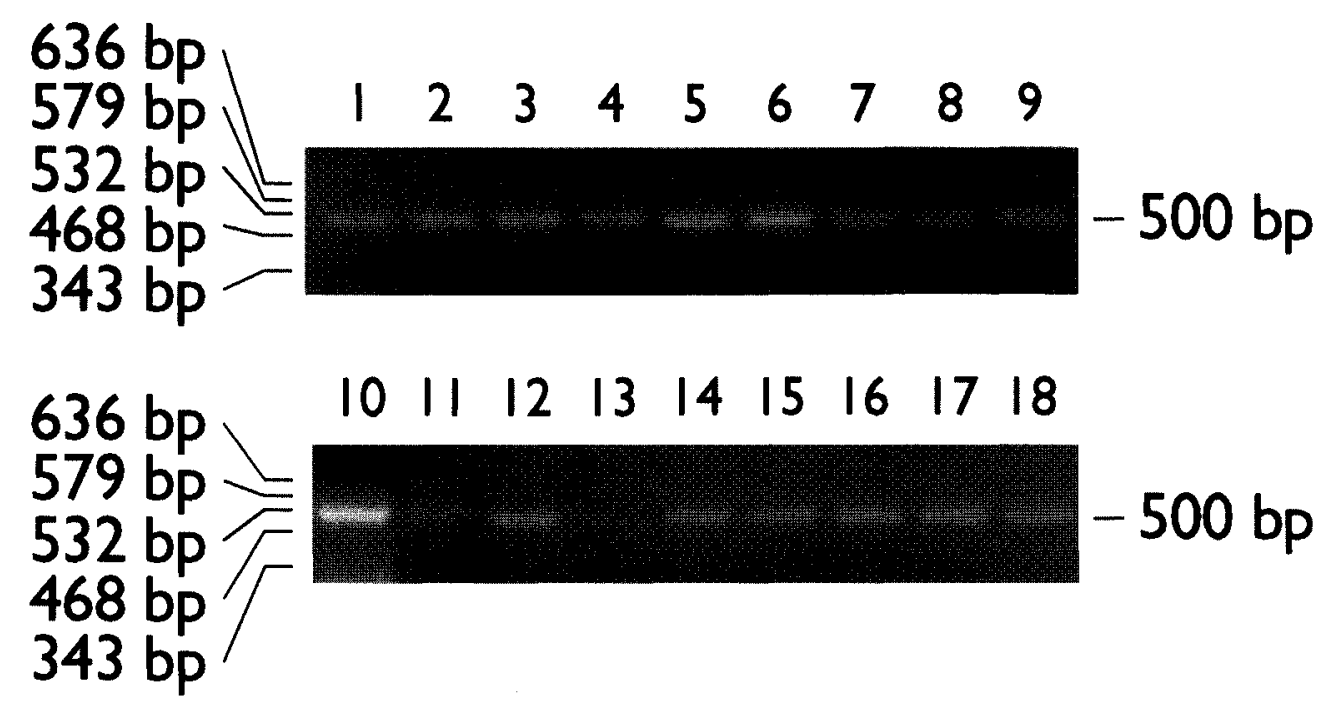

Fig. 4. Transcriptional expression of IL- $\mid \alpha$ in trophoblasts. RT-PCR yielded a single 500bp product of nearly equal intensity from trophoblasts cultured in the presence of IQ $(0,0.05,0.1,0.5,1.0$ and $5.0 \mu \mathrm{g} / \mathrm{mL}$ ) for Oh (lanes I-6), 8h (lanes $7-12$ ) and 24h (lanes 13-18).

$$
\text { IL-I } \beta
$$
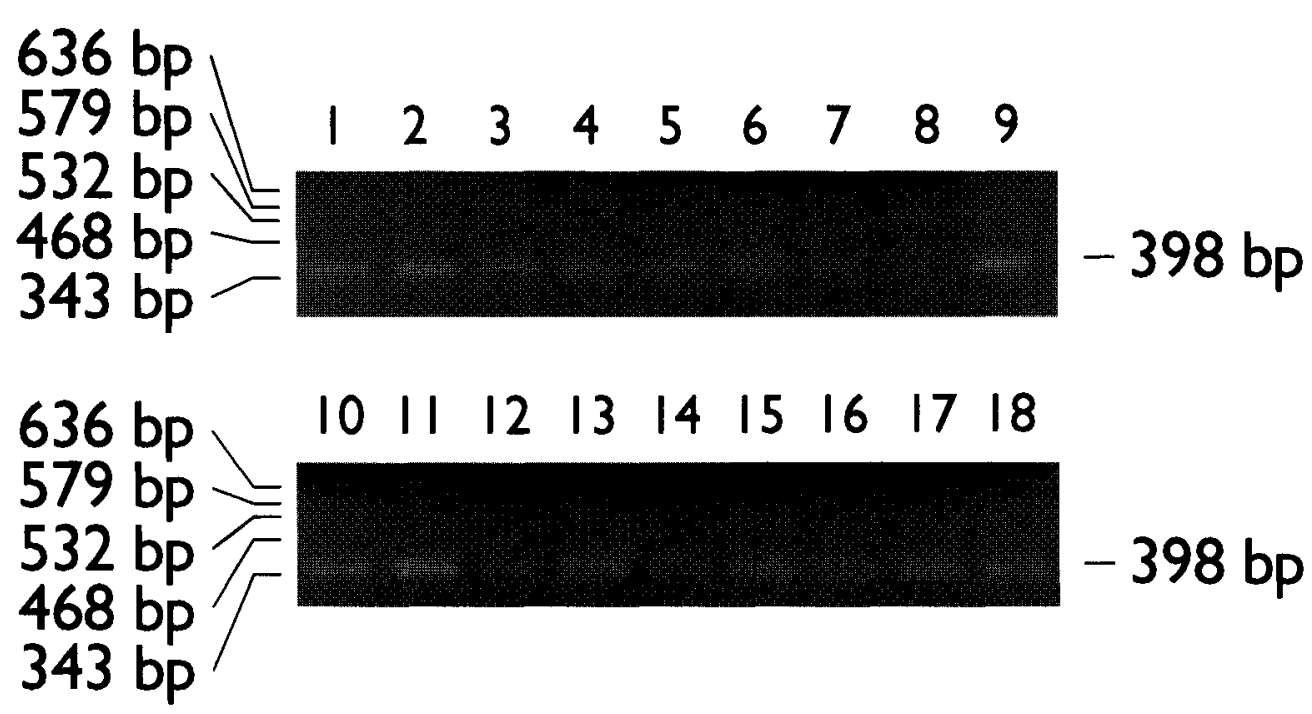

Fig. 5. Transcriptional expression of IL- I $\beta$ in trophoblasts. RT-PCR yielded a single 398bp product of nearly equal intensity from trophoblasts cultured in the presence of $\mathrm{IQ}(0,0.05,0.1,0.5,1.0$ and $5.0 \mu \mathrm{g} / \mathrm{mL}$ ) for $0 \mathrm{~h}$ (lanes $1-6)$, $8 \mathrm{~h}$ (lanes $7-12)$ and 24h (lanes 13-18). 


\section{IL-6}
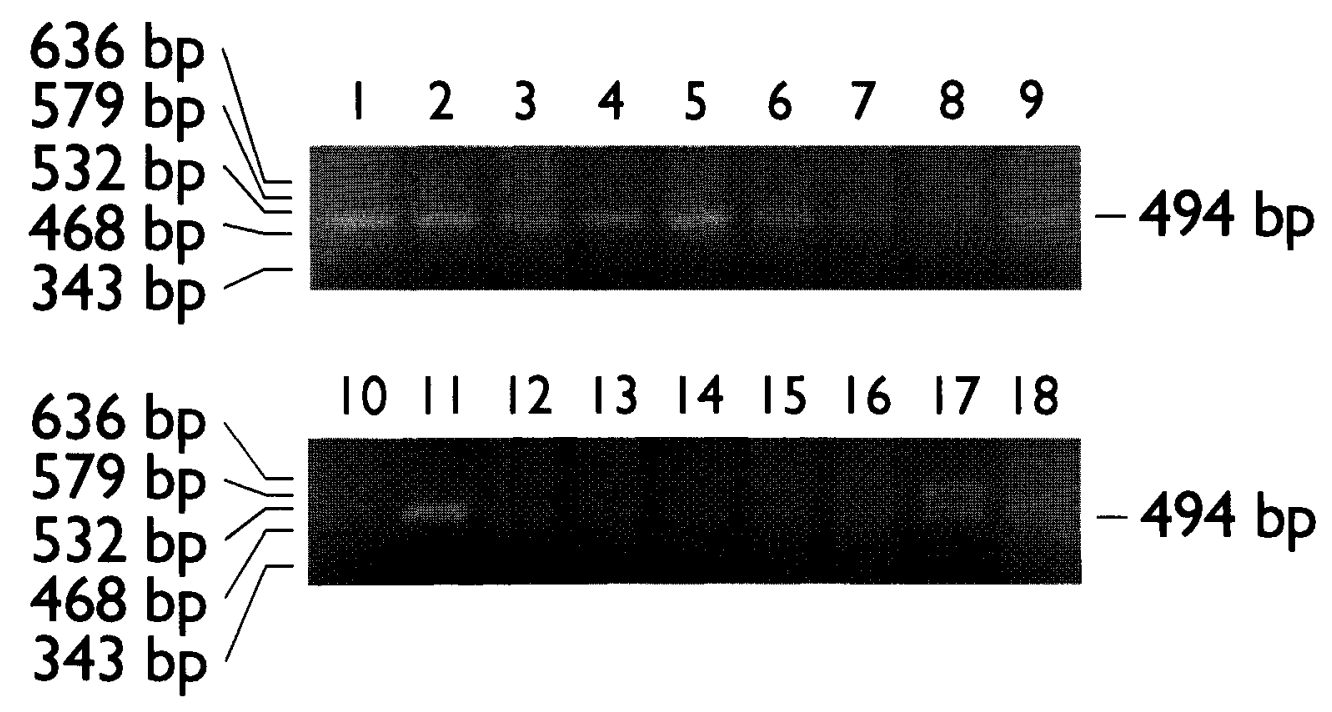

Fig. 6. Transcriptional expression of IL-6 in trophoblasts. RT-PCR yielded a major 494bp product from trophoblasts cultured in the presence of IQ $(0,0.05,0.1,0.5,1.0$ and $5.0 \mu \mathrm{g} / \mathrm{mL}$ ) for $0 \mathrm{~h}$ (lanes I-6), 8h (lanes 7-12) and 24h (lanes I3-18).

\section{IL-8}
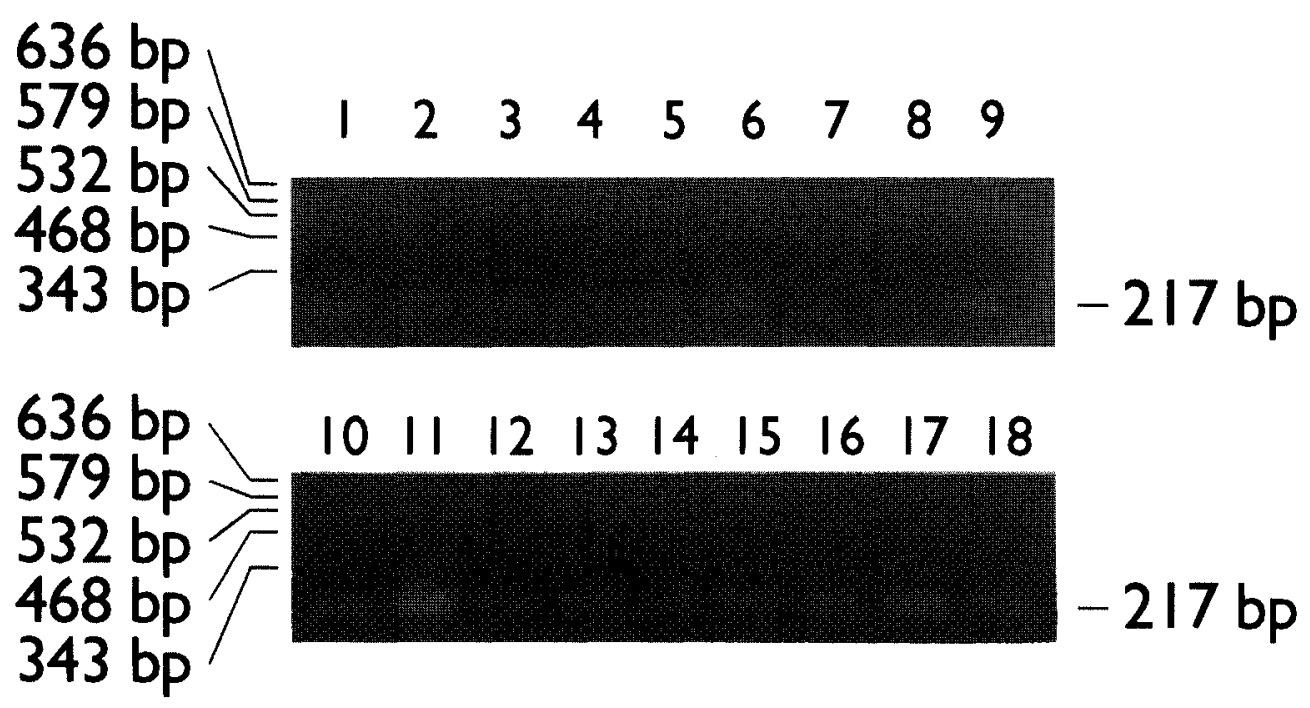

Fig. 7. Transcriptional expression of IL-8 in trophoblasts. RT-PCR yielded a single $217 \mathrm{bp}$ product of nearly equal intensity from trophoblasts cultured in the presence of $\mathrm{IQ}(0,0.05,0.1,0.5,1.0$ and $5.0 \mu \mathrm{g} / \mathrm{mL}$ ) for $0 \mathrm{~h}$ (lanes $\mathrm{I}-6)$, 8h (lanes $7-12)$ and 24h (lanes 13-18). 
does not transcriptionally induce specific proinflammatory and immunomodulatory cytokines in placental trophoblasts.

\section{CONCLUSIONS}

Imiquimod does not induce the in vitro transcription of the immunomodulatory cytokines IL-1 $\alpha$, IL-1 $\beta$, IL-6 or IL-8 in human first trimester trophoblasts. Imiquimod is therefore unlikely to alter expression of these cytokines in the placenta. The inability of imiquimod to transcriptionally induce cytokines in trophoblasts at the concentrations tested resolves some of the concerns associated with administering imiquimod during pregnancy. Imiquimod, at the levels tested, does not contraindicate use during pregnancy in humans. Further evaluation in vivo will be necessary to confirm the safety and efficacy of imiquimod during pregnancy.

\section{ACKNOWLEDGMENT}

We gratefully acknowledge Dr. Charles H. Graham, Ph.D., for his kind gift of the HTR-8/SVneo cell line.

\section{REFERENCES}

1. Testerman TL, Gerster JF, Imbertson LM, et al. Cytokine induction by the immunomodulators imiquimod and S-27609. J Leuk Biol 1995;58:365-72.

2. Weeks CE, Gibson SJ. Induction of interferon and other cytokines by imiquimod and its hydroxylated metabolite R-842 in human blood cells in vitro. J Interferon Res 1994;14:81-85.

3. Gibson SJ, Imbertson LM, Wagner TL, Testerman TL,
Reiter MJ, Miller RL, Tomai M.A. Cellular requirements for cytokine production in response to the immunomodulators imiquimod and S-27609. J Interferon Cytokine Res 1995;15:537-545.

4. Svinarich DM, Bitonti OM, Romero R, Gonik B. Induction and posttranslational expression of cytokines in a first trimester trophoblast cell line by lipopolysaccharide. Am J Obstet Gynecol 1996;175:970-73.

5. Svinarich DM, Bitonti OM, Araneda H, Romero R, Gonik B. Induction and postranslational expression of G-CSF and RANTES in a first trimester trophoblast cell line by lipopolysaccharide. Am J Reprod Immunol 1996;36:256-259.

6. Graham CH, Hawley TS, Hawley RG, MacDougall JR, Kerbel RS, Khoo N, Lala PK. Establishment and characterization of first trimester human trophoblast cells with extended lifespan. Exp Cell Res 1993;206:204 211.

7. Mosmann T. Rapid colorimetric assay for cellular growth and survival: application to proliferation and cytotoxicity assays. J Immunol Meth 1983;65:55-63.

8. Edwards L, Ferenczy A, Eron L, et al. Selfadministered topical $5 \%$ imiquimod cream for external anogenital warts. HPV Study Group. Human Papilloma Virus. Arch Derm 1998;134:25-30.

9. Beutner KR, Tyring SK, Trofatter KF Jr, et al. Imiquimod, a patient-applied immune-response modifier for treatment of external genital warts. Antimicrob. Agent \& Chemother 1998;42:789-94.

10. Dudley DJ, Trautman MS, Mitchell MD. Inflammatory mediators regulate interleukin- 8 production by cultured gestational tissues: evidence for a cytokine network at the chorio-decidual interface. J Clin Endocrinol and Metab 1993;76:404-10.

11. Wegmann TG, Guilbert LJ. Immune signaling at the maternal-fetal interface and trophoblast differentiation. Dev Comp Immunol 1992;16:425-30. 


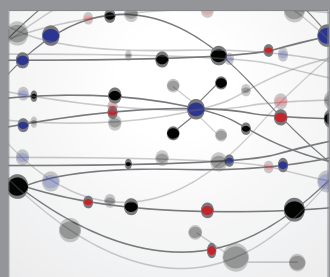

The Scientific World Journal
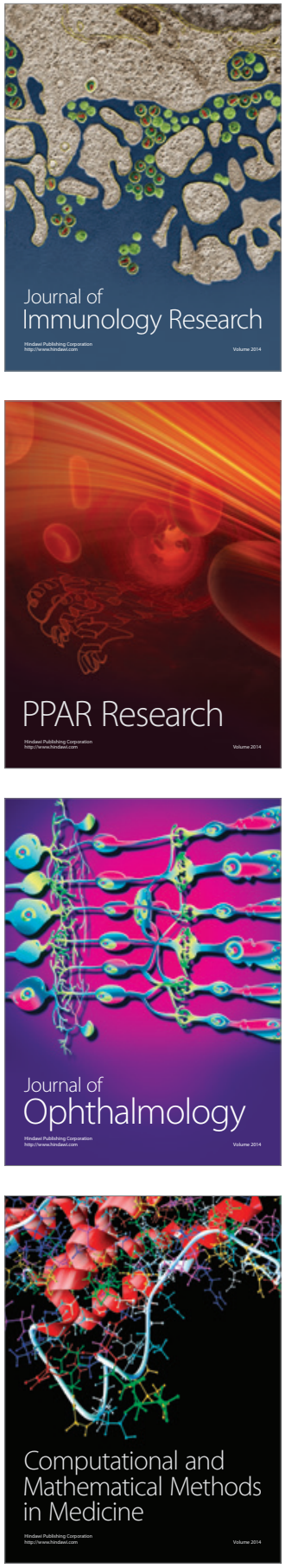

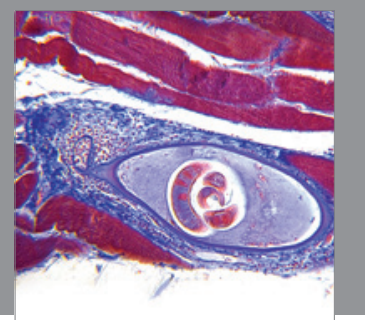

Gastroenterology

Research and Practice
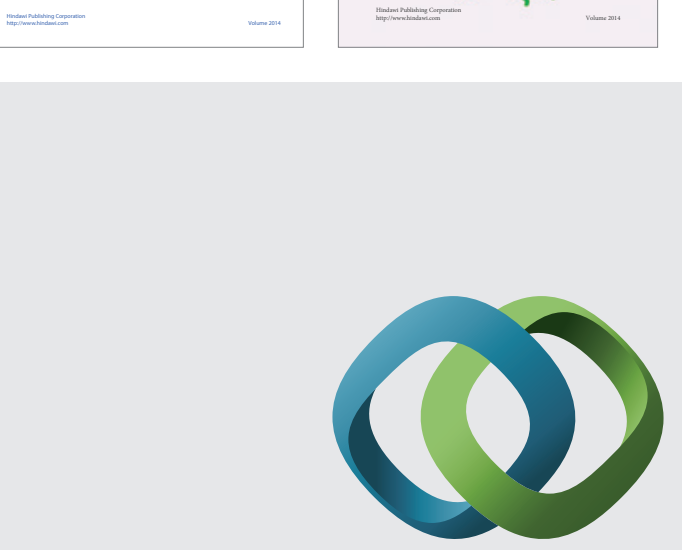

\section{Hindawi}

Submit your manuscripts at

http://www.hindawi.com
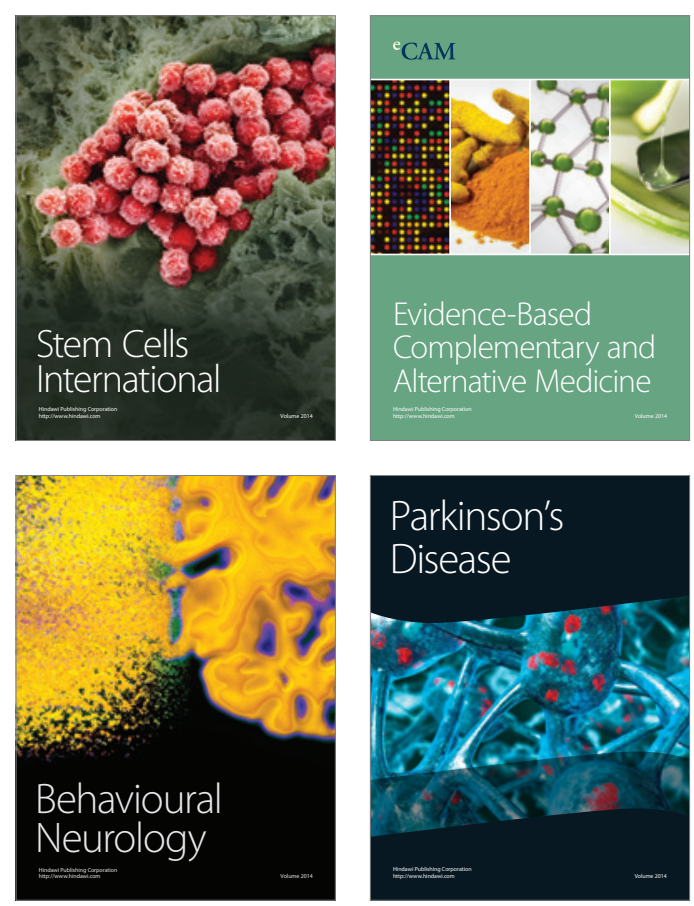

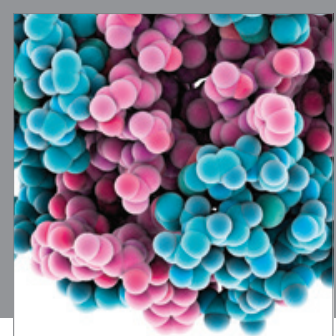

Journal of
Diabetes Research

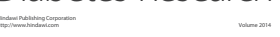

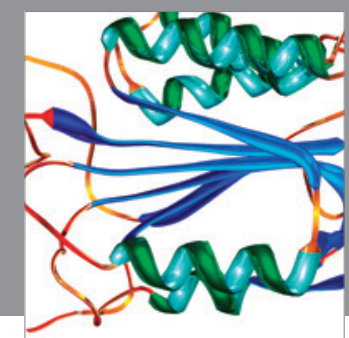

Disease Markers
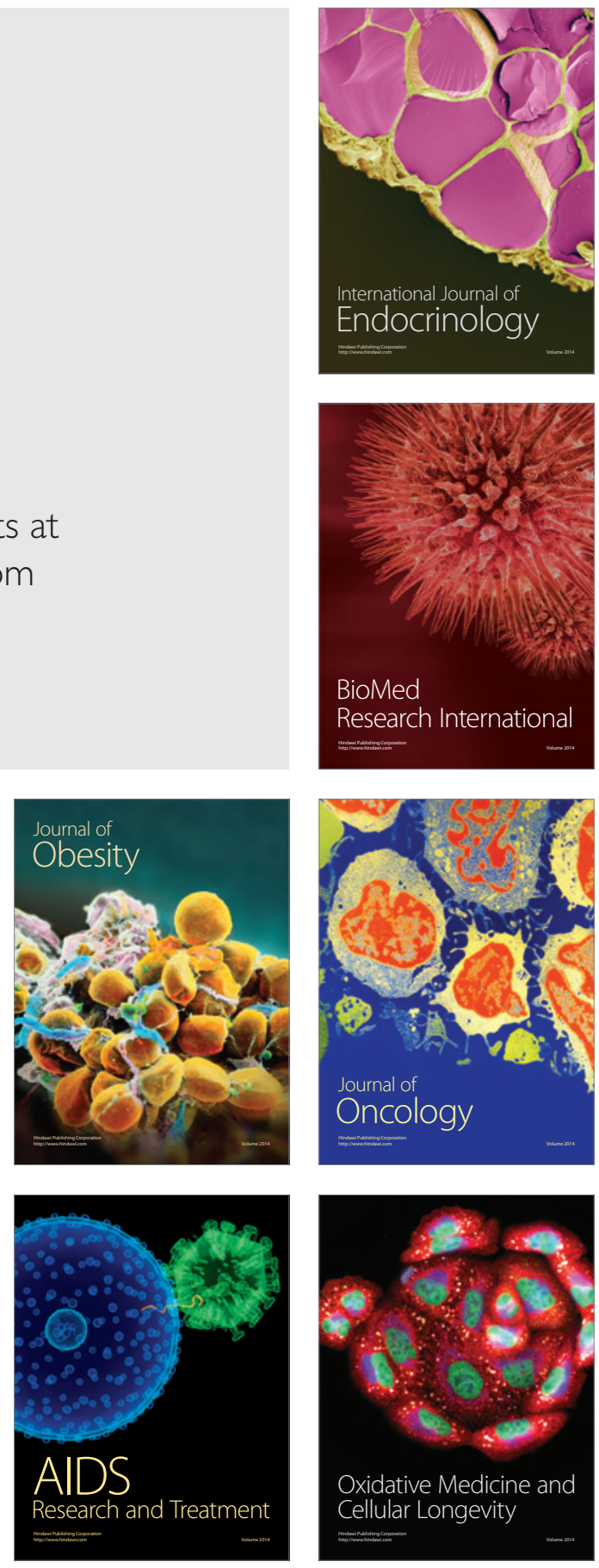